\title{
PECULIARITIES IN MANUFACTURE OF THIN-WALLED WELDED TRANSFORMABLE-VOLUME STRUCTURES FOR SPACE APPLICATION
}

\author{
L.M. LOBANOV and V.S. VOLKOV \\ E.O. Paton Electric Welding Institute, NASU \\ 11 Bozhenko Str., 03680, Kiev, Ukraine. E-mail: office@paton.kiev.ua
}

\begin{abstract}
The need in carrying out the presented investigations was predetermined by the actual problem of optimizing the process of manufacture of welded structures of a transformable-volume for long-time service under the extreme space conditions. The comparative investigations of elastic-plastic properties, and also the microstructural analysis and micromechanical investigations of welded joints of transformable-volume structures of foil materials, produced at different combinations of parameters of pulse modes of microplama welding were carried out. Feasibility of manufacture of multi-section transformable-volume structure, capable to retain the stability of service characteristics under the conditions of space factors at long-time service was shown. Optimum conditions of formation of permanent joints of thin transformable shells of steel of austenite class, combination of physical-mechanical properties and structural peculiarities of which are maximum close to similar properties of base metal were determined and confirmed experimentally. The result of the presented work demonstrates the feasibility of manufacture of transformable-volume structure with preset properties of welded joints, optimized for long-time service under the action of earlier investigated combinations of service and external factors. 7 Ref., 6 Figures.
\end{abstract}

Key words: transformable-volume structures, thin walled load-carrying shells, microplasma welding

Transformable-volume structures (TVS), developed at the E.O. Paton Electric Welding Institute (PWI), represent the load-carrying structures on base of convex closed shells of a zero Gaussian curvature, capable to change one of their dimensions many times and within the wide ranges, however, preserving a spatial rigidity, stability and integrity of the surface material. These properties of the load-carrying shells make it possible to apply them in the space industry, where the launch of structure to the near-earth orbit in a compact form can become the solution of problem of optimizing its mass-dimensional characteristics.

As a structural material of the shell the metals of a definite range of elastic-plastic properties, in particular, at ratio of yield strength $\sigma_{\mathrm{y}}$ to tensile strength $\sigma_{\mathrm{t}}$ in the range of $\sigma_{\mathrm{y}} / \sigma_{\mathrm{t}}=0.3-0.8$ are used. These are aluminium alloys, high-alloy austenitic steels, titanium, etc. It is evident that welding is, in principle, the only method of manufacture of metal vacuum-tight shell structures. One of the main problems in manufacture of TVS shells is the attaining of combination of high physicalmechanical characteristics with a simultaneous vacuum-tightness of welds, which are subjected to a complex of effects of mechanical loads and specific

(C) L.M. LOBANOV and V.S. VOLKOV, 2015 aggressive external factors. The carried out investigations were aimed at determination of optimum conditions of formation of permanent joints of thin transformable steel shells of TVS, capable to provide the service characteristics of structures under the extreme service conditions.

Figure 1 presents the stages of manufacture of structure element of conical-type TVS, including welding of straight-linear welds of semi-product (Figure 1, $a$ ) and its subsequent transformation into flat corrugated disc (Figure $1, b$ ) by using the technology of cold volume deforming, developed at the PWI. As a material, steel strip AISI 321 of thickness $\delta=0.15-0.17 \mathrm{~mm}$ was used, the largest diameter of shell was $400 \mathrm{~mm}$. The similarity of this transformation to the isometric one allows the disc to be returned to the initial conical shape (Figure 1,c), thus creating an excessive pressure in its inner cavity after the contour pressurization. In this case small residual plastic deformations in apexes of circumferential stiffeners form corrugations, which greatly increasing the rigidity of structural conical elements and load-carrying capacity of the structure as a whole.

Scheme of isometric transformation of the shell, described by a family of continuous images of its neutral surface, assumes an isotropy of structural material of the latter, therefore, the welds should have physical-mechanical properties, equivalent to the structure base metal. The technology of volume deforming of the PWI de- 


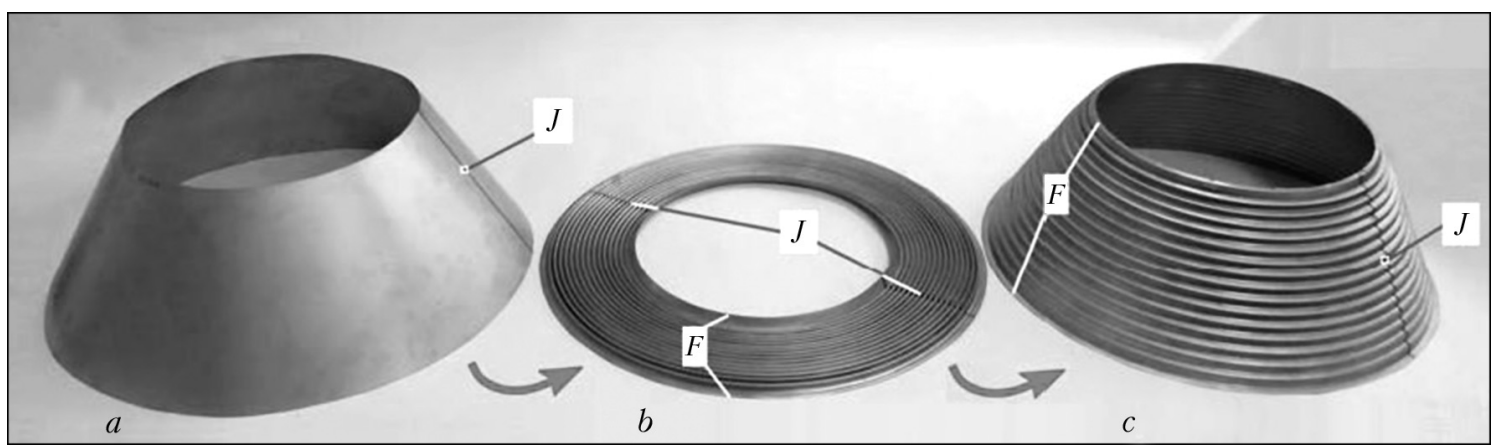

Figure 1. Stages of manufacture of transformable conical shell of TVS illustrating the nature of technological deforming of its welded joints $J$ ( $F-$ flanging for subsequent welding of shells into a single structure)

velopment assumes a continuous movement of forming tool (punch) over the shell surface, to which forming force is applied. Nevertheless, the weld geometry (reinforcement) is not decisive, as the punch during shell rotation contacts the weld root and main technological task consists in providing the quality welded joint with preset characteristics of ductility and strength.

When manufacturing the space-purpose TVS, to reduce the mass the minimum thicknesses of shell structural materials are used, at which the required strength of structure without loss of its functional properties can be provided. In selection of method for welding of butt joints of stainless steel and titanium of thicknesses $\delta=0.1-$ $0.2 \mathrm{~mm}$, microplasma welding was preferable. It allowed simplifying greatly the preparation of edges of conical semi-product for welding, thus increasing the efficiency of the TVS manufacture and decreasing the thermal deformations of weld in applying the preliminary flanging of edges being welded.

In welding of semi-products of stainless steel of $0.15-0.17 \mathrm{~mm}$ thickness the flanging of edges for value equal to two thicknesses of material was used. In addition, the microplasma welding could provide almost full repeatability of preset welding result, that can be explained by less strict requirements to accuracy of the mechanism of welding heat source movement, as compared with those specified for laser welding.

To manufacture a series of volume-transformable conical shells, the welding stand was designed (Figure 2), in which the problems of providing the precision assembly and welding of foil materials were solved at the designing level with maximum use of unified high-cost parts and units realized in advanced systems of the similar application [1]. In particular, assembly of movement mechanism with ball-screw transmission by rolling was made from separate completing parts, united into a single unit at $\pm 10 \mu \mathrm{m}$ accuracy of mutual fixation. Here, adjustments were provided, which could correct the position of the entire system of movement 1 with plasmatron 2 with respect to the plane of assembly-welding rig 3 at $\pm 25 \mu \mathrm{m}$ accuracy along each of three coordinates. Floating fixation of torch unit with respect to movement mechanism carrier 4 prevents the undesirable vibrations of plasmatron

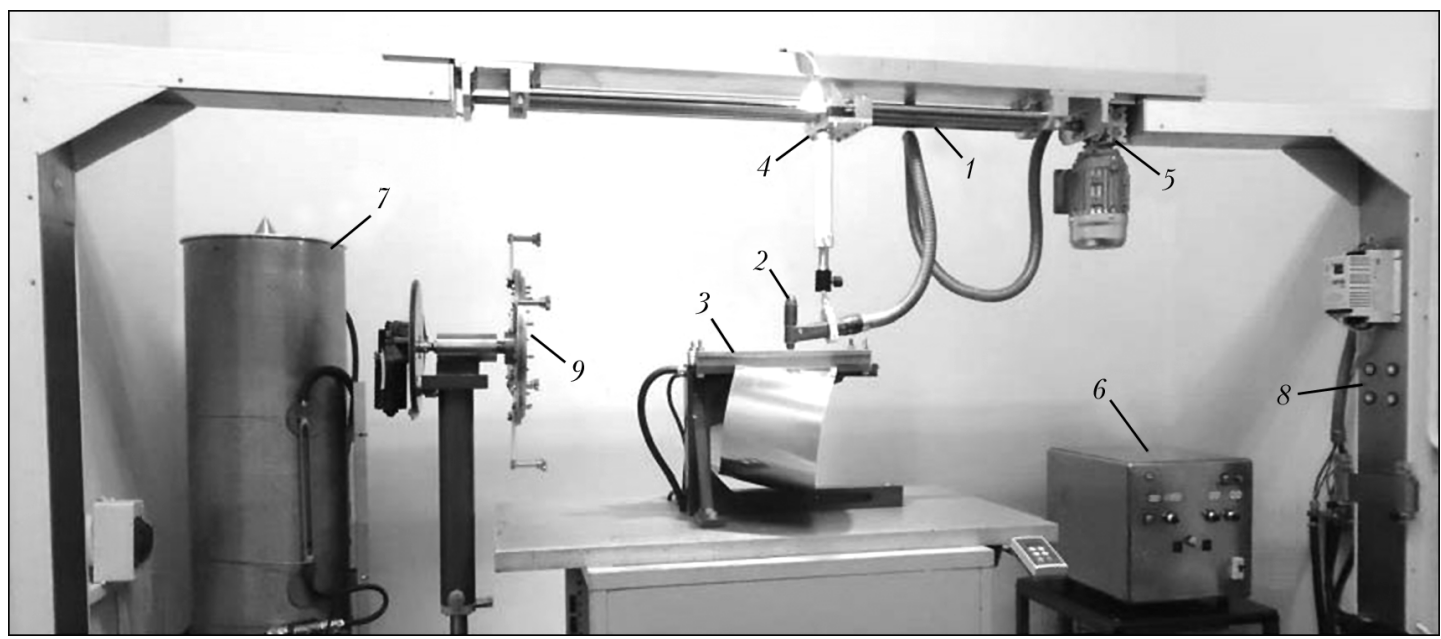

Figure 2. Experimental stand for welding of semi-products of transformable shells of foil materials: 1 - mechanism of movement; 2 - plasmatron; 3 - assembly-welding rig with conical semi-product of TVS shell; 4 - carrier of movement mechanism; 5 - motor with reducer; 6 - microplasma welding power source; 7 - heat-exchange module of plasmatron; 8 - automatic system of position adjustment of welding process parameters; 9 - device for welding of TVS circumferential welds 
during welding, and the combination of characteristics of motor, reducer with hollow shaft 5 and frequency transducer allowed avoiding the deviations in welding speed in the range of 1$25 \mathrm{~mm} / \mathrm{s}$, connected with kinematical error of the involute gearing. The equipment includes power source 6 for microplasma welding of the PWI design, providing the high stability of characteristics at welding currents of $1 \mathrm{~A}$ and higher.

The unique PWI developments were used also for designing the subassemblies of plasmatron, its cooling system and assembly-welding rig, which provides the deformation-free welding and effective protection of permanent joints of foil class metals.

Determination of range of energy inputs, at which the stable formation of quality straight-linear permanent joints of the foil class metal is possible in use of microplasma welding, does not encounter difficulties and described in works [2-4]. At the same time the conformity to the above-mentioned range can be attained at different welding conditions (at direct current or in pulsed mode) and in different combinations of parameters of pulsed mode (Figure 3), determining the different degree of the microstructure heterogeneity and distribution of alloying elements in weld metal and near-weld zone, as well as deviations of microhardness in weld section. At other equal conditions the optimality of mentioned characteristics, and also their combination with the best elastic-plastic and strength properties of permanent joints was the main criterion of selection between different groups of welding process parameters.

Determination of optimum parameters of welding process and next manufacture of thinwalled elements (sections) of the TVS were carried out in the specially designed assembly-welding rig, providing the rigid fixation of edges of foil conical semi-products at the length of some tens of centimeter at the absence of welding warping, effective removal of heat from the weld zone and maximum simplicity of assembly operation (see Figures 2 and 3). Protection of weld root with its simultaneous forced-convective cooling was attained by the inert gas pumping through a series of successive holes of alternate section in the protection channel, mated with collector. The depth, section and configuration of holes, as well as the cleanness of treatment of their edges allow reaching at the entire length of weld root almost the laminar flowing with full opening of the jet and at equal flow rates for shielding gases of different density at their consumption in the range of $5-10 \mathrm{dm}^{3} / \mathrm{min}$. At preset current value $I_{\mathrm{sp}}$ and filling coefficient $D$ the correction of energy input $Q_{1}$ at different frequencies $f_{\mathrm{pc}}$ was provided

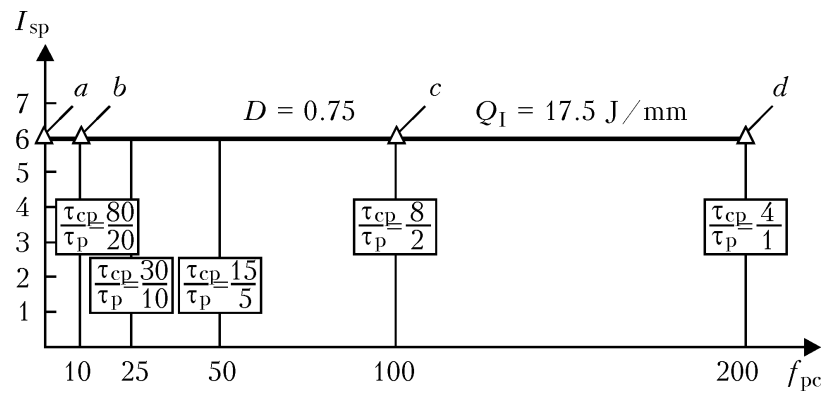

Figure 3. Combinations of parameters of pulsed conditions in microplasma welding of transformable conical shell of AISI 321 steel strip $0.17 \mathrm{~mm}$ thick: $I_{\mathrm{sp}}$ - current of straight polarity, $\mathrm{A} ; f_{\mathrm{pc}}-$ frequency of pulsed current, $\mathrm{Hz} ; \tau_{\mathrm{cp}}-$ duration of current pulse, ms; $\tau_{\mathrm{p}}-$ duration of pause, ms; $Q_{1}-$ energy input of welding; $D=\tau_{\mathrm{cp}} /\left(\tau_{\mathrm{cp}}+\tau_{\mathrm{p}}\right)-$ coefficient of filling; $a, b, c, d-$ basic combinations of parameters

by the change of volume consumptions of plasma and shielding gases at their unchanged optimum ratio, obtained empirically for selected parameters of the plasmatron and equal to about 0.32 at argon applying. Limitation of frequency of pulsed current by value $f_{\mathrm{pc}}=200 \mathrm{~Hz}$ was a need in search for optimum criteria of the quality of joints in the range of source parameters, not causing the quick wear of electrode and chamber of plasmatron plasma formation and, as a consequence, the violation of the stationary mode of welding.

Results of metallographic examinations of typical specimens from the series of welded joints produced at combinations of parameters, corresponding to Figure 3, are presented in Figure 4. Determined were the nature of heterogeneities of weld metal, near-weld zone and base metal of shell at variations of ratio $\tau_{\mathrm{cp}} / \tau_{\mathrm{p}}$, corresponding to different frequency of pulsed current, and also in case of welding with direct current of straight polarity at the preset value of energy input in all the combinations being examined.

Metallographic examinations, carried out in microscope «Neophot-32», illustrate the highest structural heterogeneity of series of specimens, made at SPDC (Figure 4, $a$ ). Weld microstructure over its section is characterized by non-uniformity and non-coaxility of crystallites with scattering of their sizes in width near the fusion line from 5 up to $7.5 \mu \mathrm{m}$ and from $4-5 \mu \mathrm{m}$ in the weld center up to $25 \mu \mathrm{m}$ near the weld root. Deviations of microhardness of weld and transition zone, measured by Vickers in LECO microhardness meter M-400 in DC welding are the highest: from 1920 up to $2570 \mathrm{MPa}$ at value of parameter of $2210 \mathrm{MPa}$ for the shell base metal (see Figure 4).

Microstructure of specimens, made at pulsed current with coefficient of filling $D=0.75$ at frequency 10 (Figure 4, b), 100 (Figure 4,c) and $200 \mathrm{~Hz}$ (Figure 4, $d$ ) is characterized by 

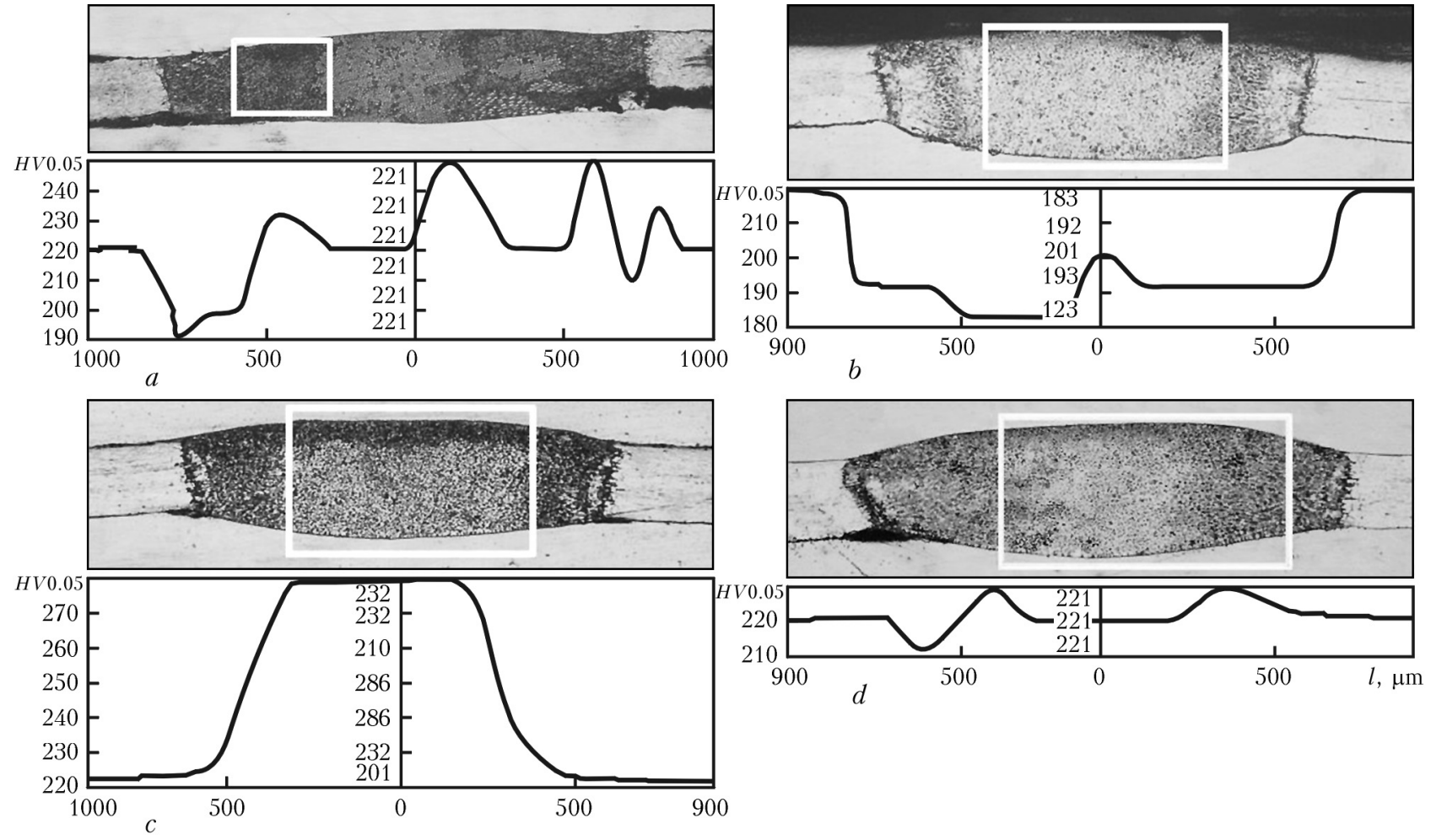

Figure 4. Results of metallographic examinations of series of welded joint specimens of AISI 321 foil $0.17 \mathrm{~mm}$ thick made at equal values of energy input using microplasma welding at SPDC $(a)$ and at pulsed current with $f_{\mathrm{pc}}=10(b)$, $100(c)$ and $200(d) \mathrm{Hz}$ (in zero point of diagram (weld middle) the values of microhardness $H V$ in vertical axis of welds are marked)

significantly higher homogeneity and co-axiality of cells at simultaneous decrease of deviations of microhardness in weld horizontal axis. In particular, the best combinations of parameters being examined were noted in series of specimens at $200 \mathrm{~Hz}$, i.e. the size of equi-axial cells corresponds to the range of 5-7 $\mu \mathrm{m}$ over all the weld section, the deviation of measured value of microhardness in any of directions of section does not exceed $5 \%$ of its value for the base metal.

In comparison of presented results with the results of testing of series of specimens, similar to groups of Figure 4, $a-d$, for static tension and bending tests, modeling the real service conditions, the closeness of elastic-plastic properties for base metal and welded joints with increase of pulsed current frequency was noted. Thus,

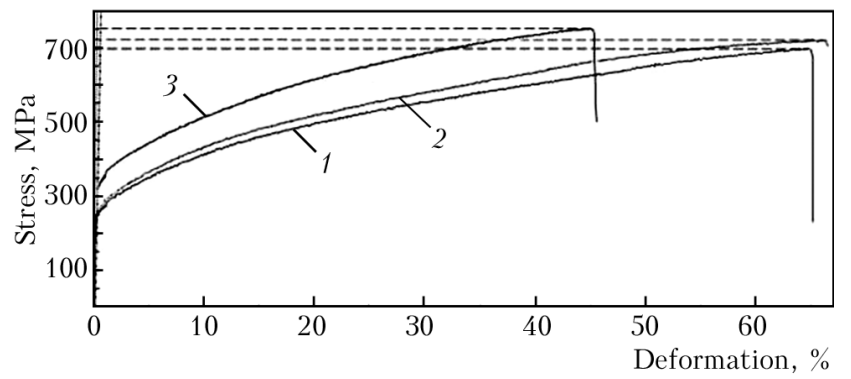

Figure 5. Diagrams of tension of specimen of $17 \mathrm{~mm}$ thick foil of steel AISI 321 without weld (1) and similar specimens made at pulsed current with $f_{\mathrm{pc}}=200 \mathrm{~Hz}(2)$ and at SPDC (3) ultimate tensile strength $\sigma_{\mathrm{t}}=724.5 \mathrm{MPa}$ and the conventional yield strength $\sigma_{0.2}=256.5 \mathrm{MPa}$ are typical of specimen of AISI 321 strip $0.17 \mathrm{~mm}$ thick with weld, made at pulsed current with $f_{\mathrm{pc}}=200 \mathrm{~Hz}$ (Figure 5, curve 2); for similar specimen without weld $\sigma_{\mathrm{t}}=699.7 \mathrm{MPa}, \sigma_{0.2}=$ $=259.2 \mathrm{MPa}$ (Figure 5, 1). Difference in the given characteristics does not exceed the errors of measurement of test system MTS ${ }^{\varpi} 318.25$, used for obtaining of experimental data. Typical diagram of tension for specimens made at SPDC is given in Figure 5, $3\left(\sigma_{t}=753.4 \mathrm{MPa}\right.$ and $\left.\sigma_{0.2}=289.3 \mathrm{MPa}\right)$.

The above-mentioned unique combination of technological and external factors in TVS service does not allow limiting by standard methods of testing in evaluating the quality of its welded structures. Vacuum of space causing desorption of shell material elements in combination with effect of radiation can be only considered conditionally as the chemically neutral environment; in transition of light-shadow boundaries at the structure surface the formation of condensates is possible with inclusions of active substances, present in natural external atmosphere of basic spacecraft for TVS. The appearance of intercrystalline corrosion, pores and microcracks, inadmissible by this reason, can be revealed by capabilities of optic microscopy at different stages of TVS manufacture by using capillary, eddy-current analysis and helium sampling. Nevertheless, the duration of action of external factors (up to 
several years), cyclic deformations caused by temperature fluctuations in the range up to $275^{\circ} \mathrm{C}$, and also natural effect of high and low temperatures require prediction of stability of properties of welded joints by their thorough study at all the structural levels. In evaluating the quality of welded joints, an integrated methodological approach to investigations of welded joints at macro- and micro level, passed a successful testing at the PWI, was realized.

In parallel with metallographic examinations, the assessment of distribution of alloying elements in weld metal was made by the method of $\mathrm{X}$-ray spectral microanalysis; the microanalyzer Camebax SX-50 (Cameca ${ }^{\circledR}$ ) with probe diameter of about $1 \mu \mathrm{m}$ at accelerating voltage $20 \mathrm{kV}$ and probe current $20 \mathrm{nA}$ was used. Curves of distribution of alloying elements were recorded in weld height and over its neutral surface. The analysis of obtained results proves that amount of alloying elements (in wt.\%) in weld metal and transition zones of specimens of Figure 4, b-d) (pulsed current) corresponds almost to similar parameters of the base metal.

The final stage of evaluation of welded joints of foil materials was the investigation of their fine structure, based on assumption about decisive effect of structural-phase state of the joint material on its physical-mechanical properties [5-7]. During investigations of dislocation structures, dislocation density and uniformity of its distribution, including structural conditions, causing the occurrence of local internal stresses in weld metal, the method of transmission microdiffraction electron microscopy (JEOL JEM200CX) was applied. Results of investigations allow making conclusion about reduction of localized deformations and structural stresses in specimens, made in use of the pulsed HF current. On the basis of the experimental-calculation estimations of contribution of structural and phase formations of the near-weld zone to the characteristics of ductility and strength the parameters of the technological process of welding were corrected. Results of work can make the conclusion about possibility of combination of the quality criteria of examined permanent joints in the range of welding process parameters, corresponding to frequencies of welding pulsed current $f_{\mathrm{pc}}=$ $=100-200 \mathrm{~Hz}$.

Optimum algorithm of conical type TVS transformation corresponds to proportions of determinative sizes, at which the ratio of conical section in unfolded position to its diameter does not exceed 0.5 value. Hence, the need in creation of structure of larger length or volume requires the uniting of many sections into single structure by their welding along their mating contours. The solution of the problem of stability of the multi-section TVS of space application and estimation of its deformability allow specifying the requirements to configuration and rigidity of welded joining elements of conical sections, in particular, the elements of smaller diameter, subjecting to the highest specific loads. The functional application of circumferential welded joints is not limited by maintaining the integrity, mechanical strength and vacuum-tightness of the multi-section long structure; the required damping properties of the latter can be provided by the peculiarities of profile of the conical surfaces of TVS in combination with rigidity of circumferential joining elements. Welding of the conical sections around the perimeters of basements unites their abutted flanges (see Figure 1,F) into single element of rigidity, i.e. ring frame, the efficiency of which depends greatly on ring width, but not on its total thickness, and also the nature of the welded joint. In particular, when welding the considered TVS flanges of smaller diameter with calculated width of $6 \mathrm{~mm}$ in the designed rotary device (see Figure 2, 9), the required result is attained by application of the combined weld, i.e. slot weld with fixation of plasmatron axis in normal to the flange plane, and then edge weld in orientation of plasmatron axis along the line of flat corrugated disc radius.

The multi-section conical TVS in compact and unfolded position at test stand of unfolding is presented in Figure 6 . The presented models of segments $(1,2)$ illustrate the scheme of making of welded joints, allowing binding the parameters of conical section into rigid ring type element of the structure. Vacuum-tight joint of edge conical section with closing element (bottom) ( $\mathrm{Fi}^{-}$ gure 6,3$)$, having material thickness $\Delta=(6-8) \delta$, where $\delta$ is the thickness of structure shell material, is performed by a preliminary welding of perimeter of section with ring of intermediate thickness $\delta_{1}=(\Delta+\delta) / 2$. Circumferential welded joints of conical TVS, unlike the straight-linear welds of the structure, are not subjected to high technological and service deformations and undergo negligible loads from internal excessive pressure of unfolding, not exceeding the value of $50 \mathrm{kPa}$. The joints can be made by the microplasma method in pulsed mode at the condition of correction of scheme of shielding gas supply for the edge welds (see Figure $6, J$ ).

The on-land cycle of tests of structure is oriented, first of all, to study of kinetics of unfolding process during the preset interval of time and under conditions, close with possible validity to the zero gravity conditions of the orbital flight. Design of vacuum-tight contour (see Figure 6, 5) will allow carrying out tests of unfolding of long TVS in different spatial positions, realizing its mass reduction simultaneously with modeling 


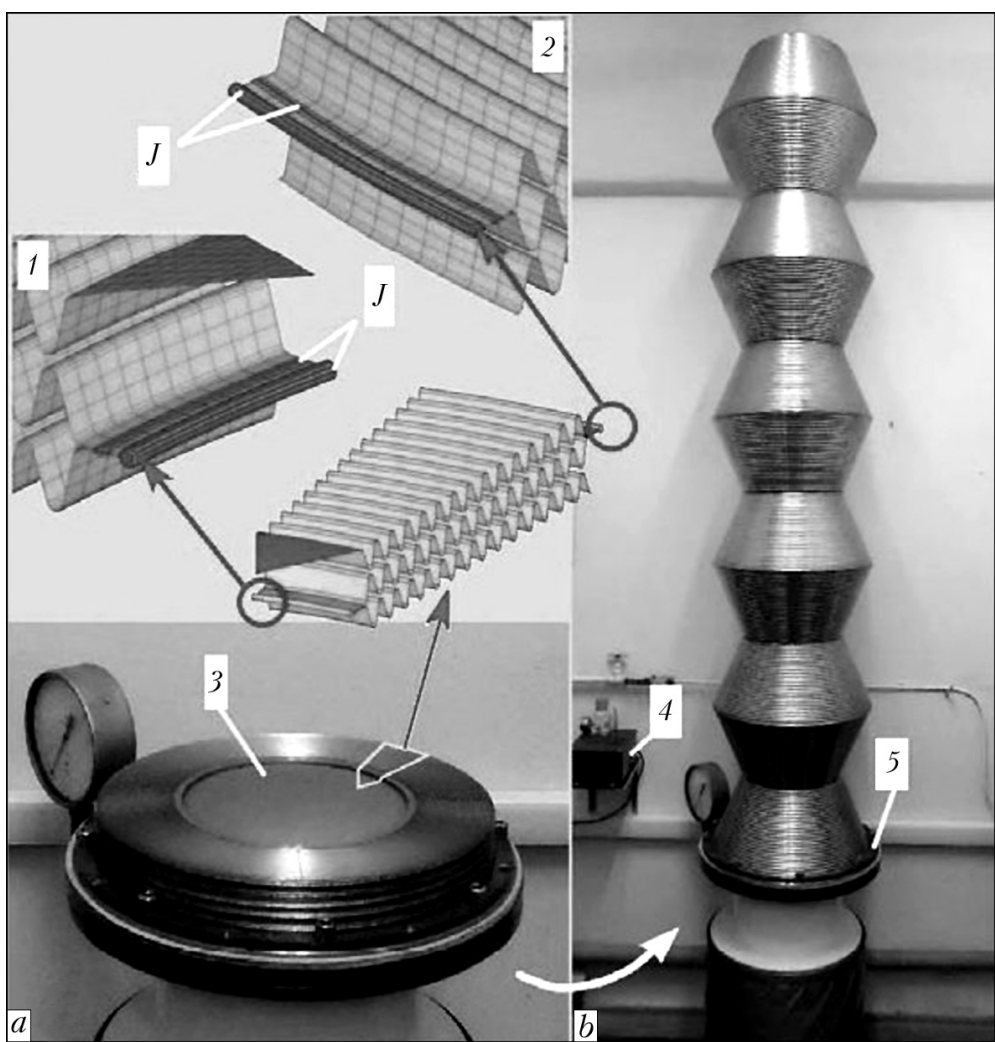

Figure 6. Conical TVS of 11 shells in the compact $(a)$ and unfolded $(b)$ positions: on the left at the top - models of segments of structure with internal (1) and external (2) circumferential welded joints $J$; 3 - closing element; 4 compact compressor with manovacuummeter; 5 - rigid vacuum-tight contour of unfolding stand

of regulated vibration actions and making the modal analysis. The scheduled vacuum tests with simulation of heat loads under the space conditions will allow evaluating the thermooptical properties of TVS surfaces and boundary temperatures, which are attained on them, thus making it possible to specify values of stresses occurred in the shell and, when necessary, to correct the configuration of ring joining elements of standard structure. In this case, the air-tightness (vacuum tightness) of the compact multi-section shell can be effectively confirmed by the advanced NDT methods.

Results of the presented work demonstrate the feasibility of TVS manufacture with preset properties of welded joints, optimized for longtime service under the action of combination of factors, not investigated earlier. By this reason, the scheduled testing of structure under the conditions of the orbital flight, which can be predicted, but cannot be reproduced at the on-land tests represents the greatest interest.

\section{Conclusions}

1. The optimum conditions of formation of permanent joints of transformable shells of foil of AISI 321 grade, the combination of physical-mechanical properties and structural peculiarities of which are maximum close to similar properties of the base metal and should provide the oper- ating characteristics of structure under extreme conditions of service, were determined and confirmed experimentally.

2. Complex of technological equipment was developed, providing the defect-free technology of microplasma welding of vacuum-tight permanent joints of foil materials under conditions of the pilot production.

3. Approaches are described for the design of multi-section TVS, capable to guarantee the serviceability of structures of this class at long-time exposure under extreme service conditions.

1. Mikrofuegetechnik GmbH. Automation + Application Technology. http: / media.mig-o-mat.com

2. Paton, B.E., Gvozdetsky, V.S., Dudko, D.A. et al. (1979) Microplasma welding. Kiev: Naukova Dumka.

3. (2008) Microjoining and nanojoining. Cambridge: Woodhead Publ.

4. Lobanov, L.M., Volkov, V.S. (2012) Development of the technology of manufacturing double-wall welded transformable-shell structure. The Paton Welding J., 10, 34-39.

5. (1997) Welding and surfacing reviews. Pt 1: Welded structures. Ed. by B. Paton, L. Lobanov. London: Taylor \& Francis.

6. Evans, G.M., Bailey, N. (1997) Metallurgy of basic weld metal. Cambridge: Woodhead Publ.

7. Nikitina, Ye.V., Frolov, V.A., Stepanov, V.V. et al. (2014) Investigation of the structural and chemical heterogeneity in welding of different groups of metallic materials. Welding Int., 28(10), 793-798.

Received 18.11.2014 